\title{
Sequential EMT-MET induces neuronal conversion through Sox2
}

\author{
Songwei He ${ }^{1,2,3,4}$, Jinlong Chen ${ }^{1,2,3,4}$, Yixin Zhang ${ }^{1,2,3,4}$, Mengdan Zhang ${ }^{1,2,3}$, Xiao Yang ${ }^{1,2,3}$, Yuan Li ${ }^{1,2,3}$, \\ Hao Sun ${ }^{1,2,3}$, Lilong Lin ${ }^{1,2,3}$, Ke Fan ${ }^{1,3}$, Lining Liang ${ }^{1,2,3}$, Chengqian Feng ${ }^{1,3}$, Fuhui Wang ${ }^{1,2,3}$, Xiao Zhang ${ }^{1,2,3}$, \\ Yiping Guo ${ }^{1,2,3}$, Duanqing Pei ${ }^{1,2,3}$, Hui Zheng ${ }^{1,2,3, *}$ \\ ${ }^{1}$ CAS Key Laboratory of Regenerative Biology, Joint School of Life Sciences, Guangzhou Institutes of Biomedicine and Health, \\ Chinese Academy of Sciences, Guangzhou Medical University, Guangzhou, China; ${ }^{2}$ University of Chinese Academy of Sciences, \\ Beijing, China; ${ }^{3}$ Guangdong Provincial Key Laboratory of Stem Cell and Regenerative Medicine, Guangzhou, China
}

Direct neuronal conversion can be achieved with combinations of small-molecule compounds and growth factors. Here, by studying the first or induction phase of the neuronal conversion induced by defined $5 \mathrm{C}$ medium, we show that the Sox2-mediated switch from early epithelial-mesenchymal transition (EMT) to late mesenchymal-epithelial transition (MET) within a high proliferation context is essential and sufficient for the conversion from mouse embryonic fibroblasts (MEFs) to $\mathrm{TuJ}^{+}$cells. At the early stage, insulin and basic fibroblast growth factor (bFGF)-induced cell proliferation, early EMT, the up-regulation of Stat3 and Sox2, and the subsequent activation of neuron projection. Up-regulated Sox2 then induced MET and directed cells towards a neuronal fate at the late stage. Inhibiting either stage of this sequential EMTMET impaired the conversion. In addition, Sox2 could replace sequential EMT-MET to induce a similar conversion within a high proliferation context, and its functions were confirmed with other neuronal conversion protocols and MEFs reprogramming. Therefore, the critical roles of the sequential EMT-MET were implicated in direct cell fate conversion in addition to reprogramming, embryonic development and cancer progression.

Keywords: $\mathrm{TuJ}^{+}$cells; sequential EMT-MET; proliferation; Sox2

Cell Discovery (2017) 3, 17017; doi:10.1038/celldisc.2017.17; published online 30 May 2017

\section{Introduction}

Neural stem cells (NSCs) and neurons induced directly from somatic cells have the potential to treat neurodegenerative diseases, such as Alzheimer's disease and Parkinson's disease [1, 2]. Methods that directly induce NSCs have been optimized from using the four Yamanaka factors, Oct4, Klf4, c-Myc and Sox2, to using only small-molecule compounds and a hypoxic environment $[3,4]$. Protocols to induce functional neurons have evolved from using combinations of transcription factors, including Ascl1, Brn2 and

\footnotetext{
${ }^{4}$ These authors contributed equally to this work.

*Correspondence: Duanqing Pei

Tel: +86 20 32015201; Fax: +862032015231

E-mail: pei_duanqing@gibh.ac.cn

or Hui Zheng

Tel: +86 20 32015334; Fax: +862032015231

E-mail: zheng_hui@gibh.ac.cn

Received 1 March 2017; accepted 26 April 2017
}

Myt11, to using a single transcription factor, neuronal differentiation 1 (NeuroD1) [5, 6]. In 2015, five reports from four laboratories, including ours, induced neurons or neuron-like cells in vitro and in vivo using only small-molecule compounds and growth factors, both from mouse and human somatic cells [7-11].

The reported neuronal conversions all included two phases and used two mediums, the initial induction medium in the induction phase and the late maturation medium in the maturation phase $[8,9,11]$. The initial induction medium induced somatic cells towards neuron-like or $\mathrm{TuJ}^{+}$cells, and the late maturation medium further converted $\mathrm{TuJ}^{+}$cells to functional neurons. Because maturation medium alone cannot induce $\mathrm{TuJ}{ }^{+}$cells, initial induction medium is critical to induce neuronal characteristics during the conversion although it cannot fully generate functional neurons. In addition, the major differences among these five protocols lie in the small-molecule compounds used in the induction phase, although valproic acid (VPA, 
histone deacetylase inhibitor), CHIR99021 (glycogen synthase kinase 3 inhibitor) and forskolin/cAMP (cAMP inducer) have been used in at least three protocols [7-11]. Thus the mechanisms underlying the initial induction phase were focused in the current investigations.

In our previous report, neuronal characteristics can be induced with simple defined 5C medium, which only includes DMEM/F12, N2, bFGF, leukemia inhibitory factor, vitamin $\mathrm{C}$ and 2-mercaptoethanol [11]. Based on the morphological and gene expression changes during the conversion with $5 \mathrm{C}$ medium [11], we propose a sequential epithelial-mesenchymal transition (EMT)-mesenchymal-epithelial transition (MET), which has been reported during embryonic development, cancer progression and the generation of induced pluripotent stem cells (iPSCs) [12-14]. We hypothesized that the early EMT may poise the cells in a state more suitable for further cell fate conversion $[15,16]$. This hypothesis was first tested during the $5 \mathrm{C}$-induced conversion and then during the conversions with other protocols.

\section{Results}

\section{Facilitated proliferation and migration during the conversion}

5C medium converts mouse embryonic fibroblasts (MEFs) into neuron-like cells or $\mathrm{TuJ}^{+}$-positive cells within 14 days. However, these neuron-like cells or $\mathrm{TuJ}^{+}$-positive cells are not fully functional neurons [11]. These neuron-like cells can be further converted to neurons by using maturation medium. The other reported protocols which use small-molecule compounds to induce direct neuronal conversions also include at least two phases [7-10], the earlier induction phase and the later maturation phase. The induction medium converts the cell fate of MEFs to neuronal cell fate, while the maturation medium further converts the neuron-like or intermediate cells to functional neurons. As maturation medium cannot induce neuronal conversion alone, it is reasonable to suggest that the essential role of induction medium in inducing neuronal characteristics. In the current study, the mechanisms employed by the induction medium, or current $5 \mathrm{C}$ medium, to induce neuronal characteristics were investigated.

The expression of markers of fibroblasts, MEFs, primary astrocytes, neurons and NSCs were determined by quantitative PCR (qPCR) in $\mathrm{TuJ}^{+}$cells and remaining cells. Based on the gene expression listed in Supplementary Figure S1A and B, the current neuron-like cells were closer to primary neurons. As the fibroblast markers, Snail/2 and Twist2, have significant higher expression in MEFs than in primary astrocytes, while Gfap and Slcla3 are more specific for astrocytes [17], the remaining cells were closer to MEFs (Supplementary Figure S1C). Both kinds of cells were far away from primary astrocytes or NSCs.

Defined 5C medium (Supplementary Table S1) was used to treat MEF cells for 14 days, and gene expression profiles were analysed on days $0,2,5,10$, and 14 [11]. Seven clusters of enriched gene ontology terms were identified for the genes whose expression changed significantly (Figure 1a and Supplementary Table S2). Consistent with the gradual acquisition of neuronal characteristics, genes related to neuron projection and neuron cell fate (Clusters I and II) were up-regulated (Figure 1b). The expression changes of genes in Cluster III-V that related to adhesion and migration suggested a sequential EMT-MET (Figure 1c), which was further confirmed by the expression changes of EMT and MET markers (Figure 1d). Suppression of genes related to oxidative phosphorylation (Cluster VI) and cell cycle (Cluster VII) suggested a metabolic switch and proliferation regulation (Figure 1e and f).

To further establish the connection between proliferation/migration with neuronal conversion, a live-cell imaging system was then used (Supplementary Movies S1-3). Two criteria-length-to-width ratio over 5 and at least two neurite outgrowths - were used to identify neuron-like cells and resulted in a significant overlap (over 85\%) with $\mathrm{TuJ}^{+}$cells (Figure 1g). A significant increase of neuron-like or $\mathrm{TuJ}^{+}$cells was observed between days 4 and 9, which correlated with the higher proliferation rate (Figure 1h), enhanced cell migration (Figure 1i) and EMT at the early stage (Figure 1j, Supplementary Tables S3 and S4), which suggested the beneficial roles of enhanced cell proliferation and migration for the neuronal conversion.

However, a small decrease in cell migration was observed on day 2 during 5C-induced conversion (Figure 1g-j). Such decrease was attributed to the serum removal when $5 \mathrm{C}$ medium was used to replace original fetal bovine serum (FBS) medium, as pretreatment of serum-free medium inhibited proliferation partially by increasing apoptosis, promoted cells towards an epithelial state, impaired cell migration and prohibited neuronal induction by $5 \mathrm{C}$ medium (Supplementary Figure S1D-H).

Although enhanced proliferation and migration correlated with the increase of $\mathrm{TuJ}^{+}$cells at the early 
stage (days 4-9), the proliferation inhibition and migration arrest at the late stage (days 10-14) were consistent with the characteristics of mature neurons. In addition, although a constant change towards primary neurons was suggested during the current conversion (Figure 1b, Supplementary Figure S2A and $\mathrm{B}$ ), the expression changes for genes related to EMT/MET, oxidative phosphorylation (OX) and glycolysis (Gly) suggested that the late stage is more similar to neuronal conversion than the early stage (Supplementary Figure S2C-F and Supplementary Table S5). Furthermore, $B c l 2$, which facilitates the metabolic switch from glycolytic to oxidative metabolism during neuronal conversion with Ascll [18], was suppressed at the early stage and up-regulated at the late stage (Supplementary Figure S2F). Thus, the early stage of the current conversion is either redundant or is to prepare cells for further conversion.

\begin{tabular}{|c|c|c|c|c|}
\hline & & GO ID & GO Name & $P$ value \\
\hline \multirow{5}{*}{ 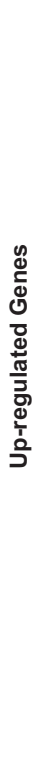 } & 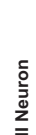 & $\begin{array}{l}\text { GO: } 0031175 \\
\text { GO:0048812 } \\
\text { GO:0007409 } \\
\text { GO:0007411 } \\
\text { GO:0048666 } \\
\text { GO:0030182 }\end{array}$ & $\begin{array}{l}\text { Neuron projection Development } \\
\text { Neuron Projection morphogenesis } \\
\text { Axonogenesis } \\
\text { Axon guidance } \\
\text { Neuron development } \\
\text { Neuron differentiation }\end{array}$ & $\begin{array}{l}3.12 \mathrm{E}-09 \\
5.20 \mathrm{E}-09 \\
3.13 \mathrm{E}-08 \\
2.93 \mathrm{E}-06 \\
4.00 \mathrm{E}-06 \\
2.83 \mathrm{E}-05\end{array}$ \\
\hline & 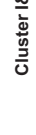 & $\begin{array}{l}\text { GO: } 0019228 \\
\text { GO:0008366 } \\
\text { GO:0007272 } \\
\text { GO:0001508 } \\
\text { GO:0042552 } \\
\text { GO:0019226 }\end{array}$ & $\begin{array}{l}\text { Regulation of action potential in neuron } \\
\text { Axon ensheathment } \\
\text { Ensheathment of neurons } \\
\text { Regulation of action potential } \\
\text { Myelination } \\
\text { Transmission of nerve impulse }\end{array}$ & $\begin{array}{l}1.49 \mathrm{E}-07 \\
3.87 \mathrm{E}-07 \\
3.87 \mathrm{E}-07 \\
4.07 \mathrm{E}-06 \\
5.64 \mathrm{E}-06 \\
1.35 \mathrm{E}-04\end{array}$ \\
\hline & б & $\begin{array}{l}\text { GO:0031012 } \\
\text { GO:0005578 } \\
\text { GO:0044421 } \\
\text { GO:0044420 } \\
\text { GO:0005576 }\end{array}$ & $\begin{array}{l}\text { Extracellular matrix } \\
\text { Proteinaceous extracellular matrix } \\
\text { Extracellular region part } \\
\text { Extracellular matrix part } \\
\text { Extracellular region }\end{array}$ & $\begin{array}{l}1.29 \mathrm{E}-27 \\
2.04 \mathrm{E}-25 \\
4.74 \mathrm{E}-20 \\
2.53 \mathrm{E}-13 \\
1.57 \mathrm{E}-11\end{array}$ \\
\hline & 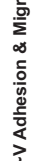 & $\begin{array}{l}\text { GO: } 0007155 \\
\text { GO:0022610 } \\
\text { GO:0030155 } \\
\text { GO: } 0016337 \\
\text { GO:0045785 } \\
\text { GO:0010810 } \\
\text { GO:0010811 }\end{array}$ & $\begin{array}{l}\text { Cell adhesion } \\
\text { Biological adhesion } \\
\text { Regulation of cell adhesion } \\
\text { Cell-cell adhesion } \\
\text { Positive regulation of cell adhesion } \\
\text { Regulation of cell-substrate adhesion } \\
\text { Positive regulation of cell-substrate adhesion }\end{array}$ & $\begin{array}{l}1.78 \mathrm{E}-22 \\
2.13 \mathrm{E}-22 \\
2.34 \mathrm{E}-08 \\
4.75 \mathrm{E}-06 \\
1.03 \mathrm{E}-05 \\
1.74 \mathrm{E}-05 \\
5.00 \mathrm{E}-04\end{array}$ \\
\hline & 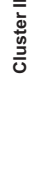 & $\begin{array}{l}\text { GO: } 0006928 \\
\text { GO:0016477 } \\
\text { GO:0051674 } \\
\text { GO:0048870 } \\
\text { GO:0051270 } \\
\text { GO:0040012 } \\
\text { GO:0030334 } \\
\text { GO:0051272 }\end{array}$ & $\begin{array}{l}\text { Cell motion } \\
\text { Cell migration } \\
\text { Localization of cell } \\
\text { Cell motility } \\
\text { Regulation of cell motion } \\
\text { Reegulation of locomotion } \\
\text { Regulation of cell migration } \\
\text { Positive regulation of cell motion }\end{array}$ & $\begin{array}{l}1.25 \mathrm{E}-09 \\
6.75 \mathrm{E}-07 \\
5.72 \mathrm{E}-05 \\
5.72 \mathrm{E}-05 \\
6.22 \mathrm{E}-06 \\
5.48 \mathrm{E}-04 \\
5.54 \mathrm{E}-04 \\
5.17 \mathrm{E}-03\end{array}$ \\
\hline \multirow{2}{*}{ 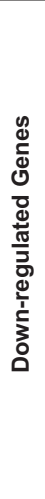 } & 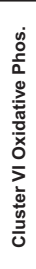 & $\begin{array}{l}\text { GO: } 0044429 \\
\text { GO: } 0005740 \\
\text { GO: } 0031966 \\
\text { GO: } 0005743 \\
\text { GO:0019866 } \\
\text { GO:0031967 } \\
\text { GO:0031975 } \\
\text { GO::0070469 } \\
\text { GO::0006091 } \\
\text { GO::0022900 } \\
\text { GO: } 0031090 \\
\text { GO: } 0055114\end{array}$ & $\begin{array}{l}\text { Mitochondrial part } \\
\text { Mitochondrial envelope } \\
\text { Mitochondrial membrane } \\
\text { Mitochondrial inner membrane } \\
\text { Organelle inner membrane } \\
\text { Organelle envelope } \\
\text { Envelope } \\
\text { Respiratory chain } \\
\text { Generation of precursor metabolites \& energy } \\
\text { Electron transport chain } \\
\text { Organelle membrane } \\
\text { Oxidation reduction }\end{array}$ & $\begin{array}{l}4.32 \mathrm{E}-61 \\
9.17 \mathrm{E}-41 \\
3.96 \mathrm{E}-40 \\
2.83 \mathrm{E}-38 \\
9.51 \mathrm{E}-38 \\
6.84 \mathrm{E}-36 \\
1.15 \mathrm{E}-35 \\
1.80 \mathrm{E}-26 \\
3.78 \mathrm{E}-23 \\
4.50 \mathrm{E}-23 \\
1.44 \mathrm{E}-20 \\
1.48 \mathrm{E}-07\end{array}$ \\
\hline & 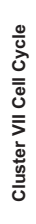 & $\begin{array}{l}\text { GO: } 0000087 \\
\text { GO: } 0007049 \\
\text { GO: } 0007067 \\
\text { GO: } 0000280 \\
\text { GO:0048285 } \\
\text { GO: } 0000278 \\
\text { GO:0051301 } \\
\text { GO::0000279 } \\
\text { GO::0022403 } \\
\text { GO:0022402 }\end{array}$ & $\begin{array}{l}\text { M phase of mitotic cell cycle } \\
\text { Cell cycle } \\
\text { Mitosis } \\
\text { Nuclear division } \\
\text { Organelle fission } \\
\text { Mitotic cell cycle } \\
\text { Cell division } \\
\text { M phase } \\
\text { Cell cycle phase } \\
\text { Cell cycle process }\end{array}$ & $\begin{array}{l}2.64 \mathrm{E}-18 \\
3.65 \mathrm{E}-18 \\
1.76 \mathrm{E}-17 \\
1.76 \mathrm{E}-17 \\
2.73 \mathrm{E}-17 \\
8.86 \mathrm{E}-16 \\
1.16 \mathrm{E}-15 \\
1.80 \mathrm{E}-15 \\
2.29 \mathrm{E}-14 \\
6.00 \mathrm{E}-14\end{array}$ \\
\hline
\end{tabular}

b
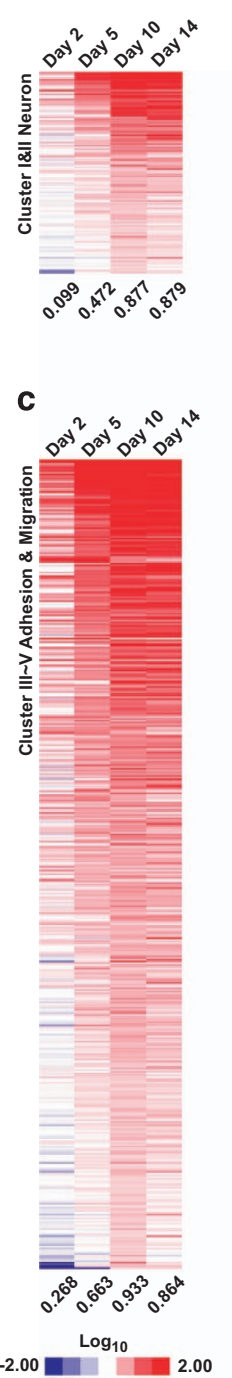

d

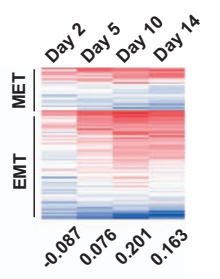

e

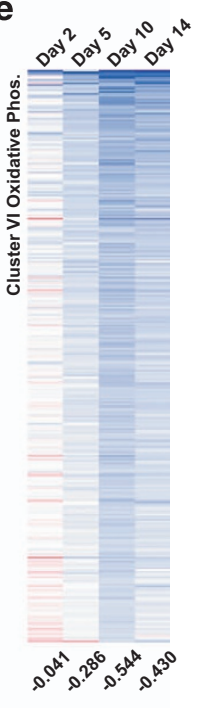

f

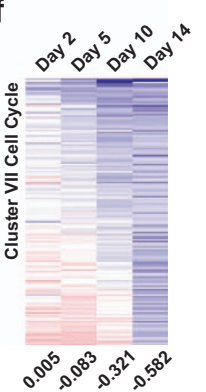

g

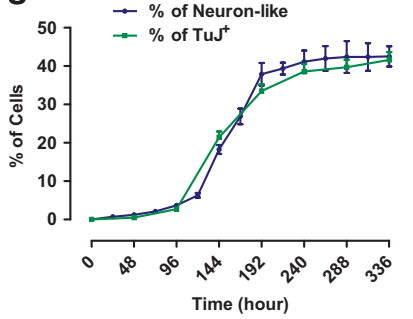

h
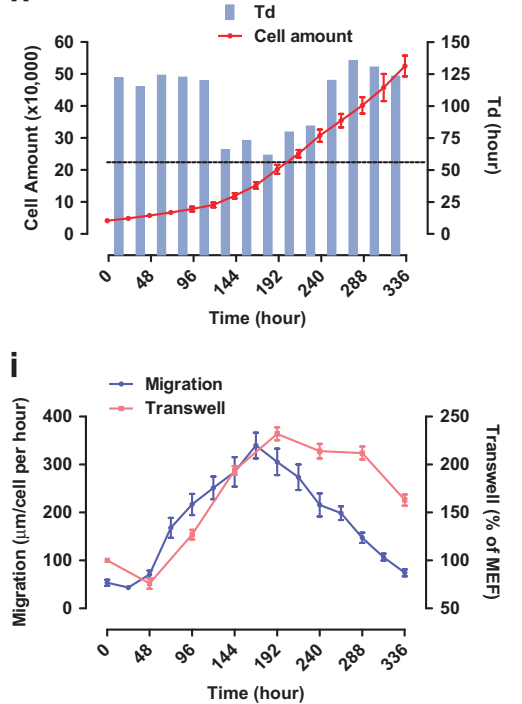

j $\rightarrow$ EMT GPCR

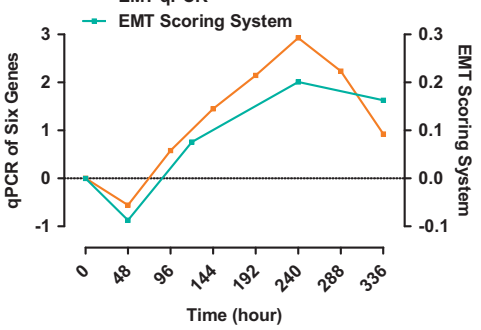

Figure 1 Cell proliferation and migration are induced during the conversion. (a-f) RNA-seq was performed during 5C-induced neuronal conversion. Genes with significant expression changes (over twofold) were enriched in seven gene ontology (GO) clusters (a). Heatmaps were used to summarize the expression changes of genes in these seven clusters (b-f). Averages of the $\log _{2}$ values (EMT scores in $\mathbf{d}$ ) are provided below the heatmaps. ( $\mathbf{g}-\mathbf{j})$ Percentages of neuron-like and $\mathrm{TuJ}^{+}$cells were determined by cell morphology and immunofluorescence, respectively, and were consistent with each other $(\mathbf{g})$. Cell amounts and doubling times are plotted in $\mathbf{h}$. Distances that cells migrated and transwell results are summarized in i. The EMT scores based on RNA-seq and qPCR are listed in $\mathbf{j}$. 
Early mitosis is critical for the conversion

By using the live-cell imaging system, each individual cell on day 14 during the conversion was traced back to MEFs, on day 0. Actually, three major types of cells, neuron-like, shrunken and MEF-like cells, accounted for more than $97 \%$ of the surviving cells on a

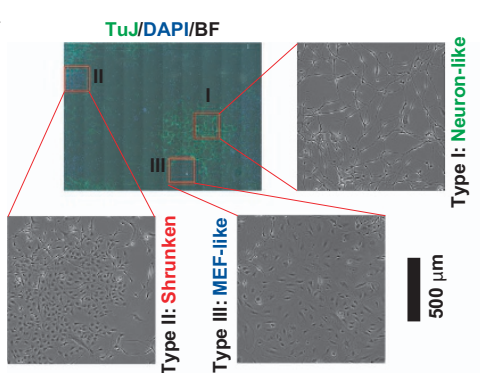

b

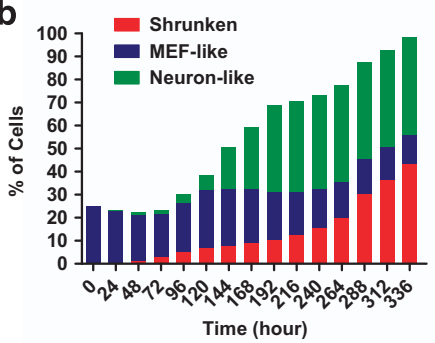

c

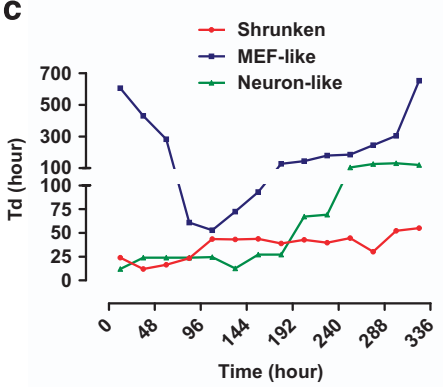

d

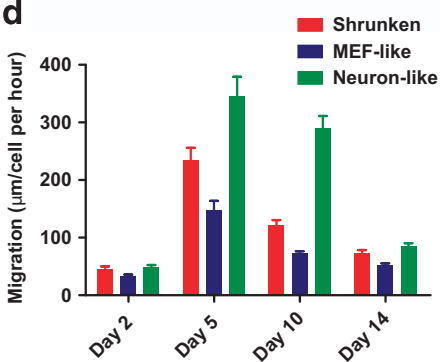

e

Become Neuron-like Cells immediately after Mitosis
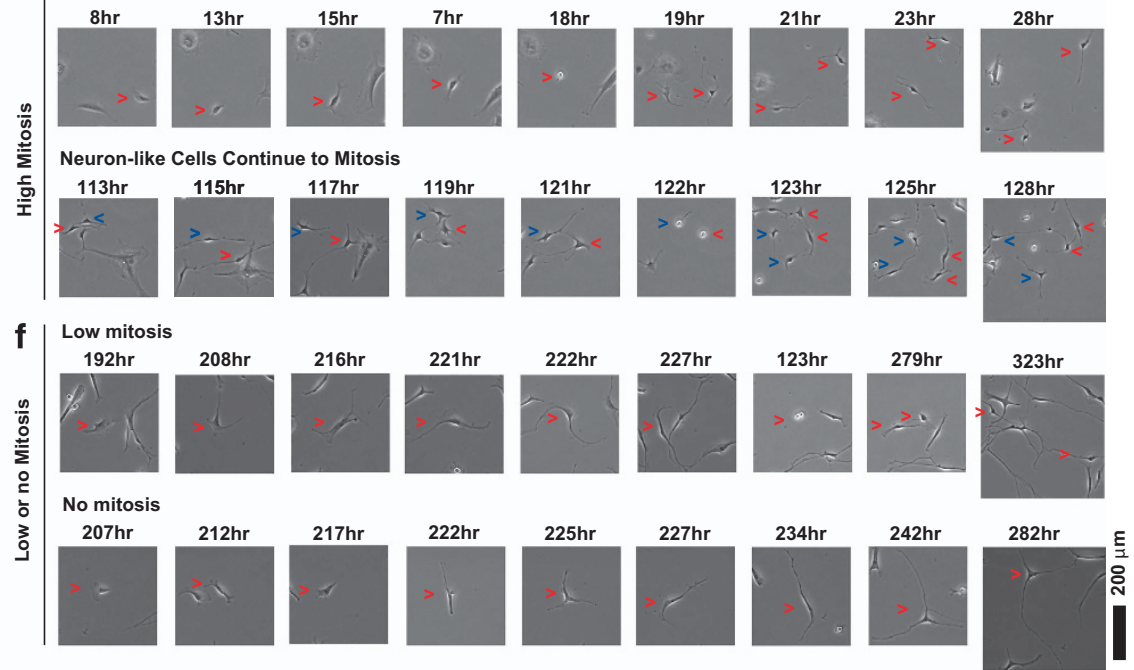

h
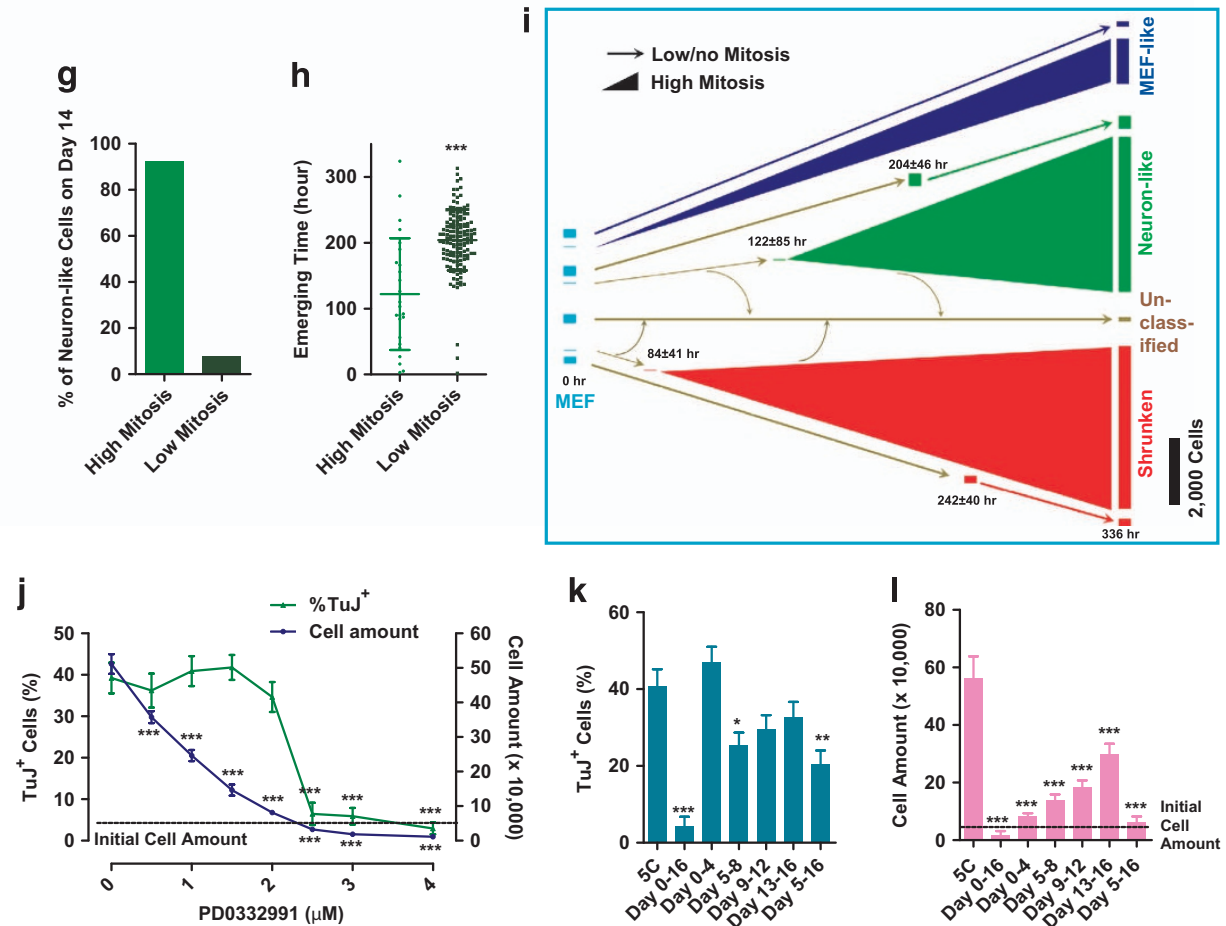

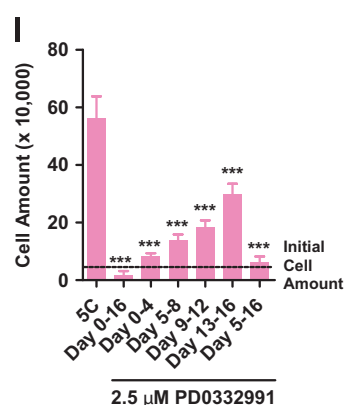

Figure 2 Induction of neuron-like cells requires mitosis. (a-d) The majority (over 97\%) of cells on day 14 were classified as neuron-like, shrunken and MEF-like cells (a). The percentages (b), doubling times (c) and migration abilities (d) of these three types of cells are summarized. (e, f) Neuron-like cells could be induced with high or low (direct conversion) mitosis. In the first picture of each line of pictures, the cells selected for tracing were marked with red arrows. These cells and their daughter cells were marked in the following pictures. When two cells were traced, red and blue arrows were used to distinguish them. (g, $\mathbf{h}) \mathrm{The}$ percentages of neuron-like cells induced with high or low mitosis are summarized after tracing 500 randomly selected MEFs (g). The averaged emerging time of these two kinds of cells are in $\mathbf{h}$. (i) Summary of the $5 \mathrm{C}$-induced conversion with 500 randomly selected MEFs. The averaged emerging time of different kinds of cells is also provided. (j-I) The concentration-dependent and time-dependent effects of PD0332991 on proliferation and TuJ ${ }^{+}$cell induction. 
day 14 (Figure 2a and b). MEF-like cells accounted for about $25 \%$ cells on day 0 but only about $10 \%$ cells on day 14, because of their low proliferation rate (Figure $2 \mathrm{~b}$ and $\mathrm{c}$ ). Neuron-like and shrunken cells were not observed at the beginning of the conversion but account for $\sim 90 \%$ cells on day 14 , because of the conversion from MEFs and high proliferation rates (Figure $2 \mathrm{~b}$ and $\mathrm{c}$ ). The migration of these three types of cells all peaked around days 5-10, which correlated with their higher proliferation in the similar time period (Figure 2c and d).

The generation of neuron-like cells was then traced with live-cell imaging. Some cells acquired neuron-like morphology immediately after one particular round of mitosis and continued to produce more neuron-like cells (Figure 2e). However, some other cells acquired neuron-like morphology with low or even no mitosis (Figure 2f). Although the number of converted cells with low mitosis was $\sim 6$-fold higher than that of cells that converted with high mitosis, their contribution to the final neuron-like cells on day 14 was only $\sim 8 \%$ (Figure $2 \mathrm{~g}$ and $\mathrm{h}$ ). In addition, the conversions of cells with low mitosis were much later than the conversion of cells with high mitosis. Thus, mitosis is critical for the induction of neuron-like cells from MEFs.

Similar phenomena were observed with shrunken and MEF-like cells. More cells were converted with low mitosis than with high mitosis, but their contributions to the final cells were less and averaged conversion time was later (Supplementary Figure S3A-F). Therefore, mitosis is essential for the conversion of all three types of cells.

As summarized in Figure 2i, $~ 53 \%$ of initial MEFs converted to neuron-like and shrunken cells either with high mitosis at the early-to-middle stage, or converted directly at the middle-to-late stage without significant mitosis. Approximately $23 \%$ and $24 \%$ of initial MEFs converted to MEF-like cells and unclassified cells, respectively. However, as MEF-like and unclassified cells suffered from the initial proliferation inhibition resulting from serum removal, and more cells underwent apoptosis during the conversion, the final percentages of MEF-like and unclassified cells converted from MEFs on day 14 were small (Supplementary Figure S3G-I).

To further confirm the contribution of cell proliferation to the conversion, the regulatory effects of the highly selective CDK4/6 inhibitor, PD0332991 [19], on conversion were then determined. PD0332991 did not significantly affect the final percentage of $\mathrm{TuJ}^{+}$ cells until concentrations of $2.5 \mu \mathrm{M}$ or higher were used, which fully blocked proliferation (Figure 2j).
In addition, PD0332991 had a greater inhibitory effect on the final number of $\mathrm{TuJ}^{+}$cells when used at the early stage and a greater inhibitory effect on the final percentage of $\mathrm{TuJ}^{+}$cells when used at the late stage (Figure $2 \mathrm{k}$ and 1 ), possibly because of the different time-dependent regulations on the proliferation of the three cell types (Figure 2c).

If cell proliferation is important, the initial cell density and activation of Notch pathway should also be important for the conversion. Actually, Notch pathway activation was observed during the conversion, especially with a high initial density of MEFs (Supplementary Figure S4A and B). Using DAPT, a $\gamma$-secretase inhibitor, to block the Notch pathway increased both the number and percentage of final $\mathrm{TuJ} \mathrm{J}^{+}$ cells, which was consistent with the Notch pathway activator Jagged1 (Supplementary Figure S4C and D). DAPT increased the percentage of $\mathrm{TuJ}^{+}$cells by supporting the further proliferation of $\mathrm{TuJ}^{+}$cells and suppressing the proliferation of other cells at the late stage (Supplementary Figure S4E and F). The optimal density of initial MEFs was between 20000 and 50000 per well in a 6-well plate (Supplementary Figure S4G).

\section{Sequential EMT-MET induced by insulin and bFGF}

We next investigated which gradient or gradients in 5C medium accounted for the stimulated proliferation. Separately purchased and mixed insulin (I), transferrin (T) and sodium selenite (S) were used to replace N2, and no difference in proliferation or conversion was observed (Figure 3a and b). Furthermore, with sodium selenite or $2 \mathrm{Me}$ (B) supplemented in the medium, both insulin and bFGF were found to be essential for proliferation and $\mathrm{TuJ}^{+}$cell induction (Figure 3a-e). Whether insulin and bFGF induced a similar conversion in the mouse brain was then determined. As indicated in Supplementary Figures S6, 5C medium and IFB (DMEM/F12 supplemented with insulin, bFGF and 2-me) medium induced better recovery, as demonstrated with increased tissue inside the lesion that resulted from medium infusion, weaker immunofluorescence response of glial fibrillary acidic protein (GFAP) and more EdU ${ }^{+}$cells inside and surrounding the lesion.

When the final cell amounts and percentages of $\mathrm{TuJ}^{+}$ cells from samples tested during factor deduction were plotted and compared to the curve generated with PD0332991, a curve shift was identified (Figures 2j and $3 \mathrm{a}-\mathrm{f}$ ), which suggested that insulin and bFGF contribute to $\mathrm{TuJ}^{+}$cell induction via other pathways in addition to promoting proliferation. The first 
a

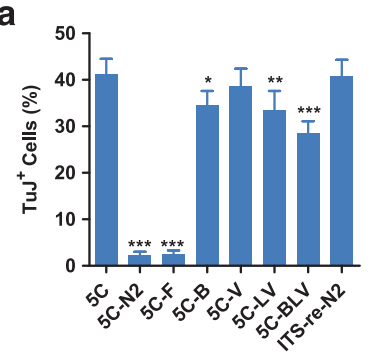

C
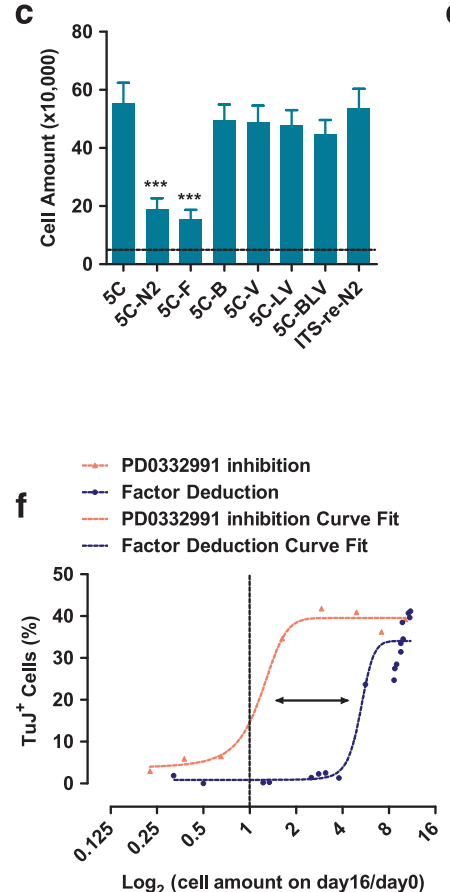

i

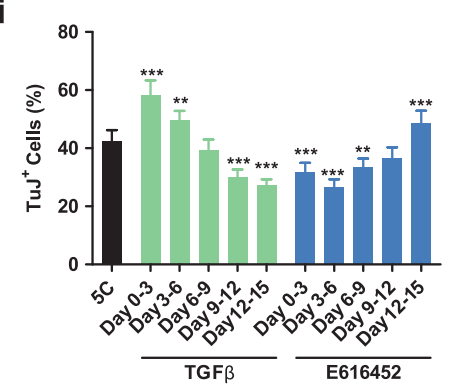

b

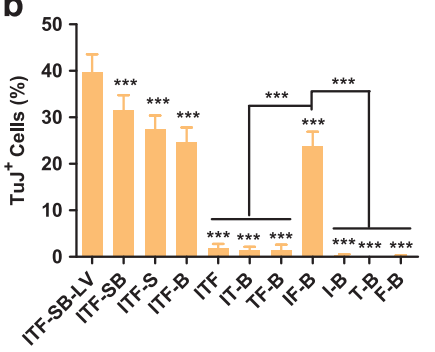

d

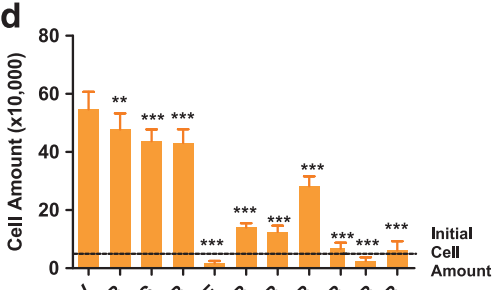

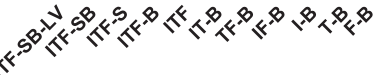

e
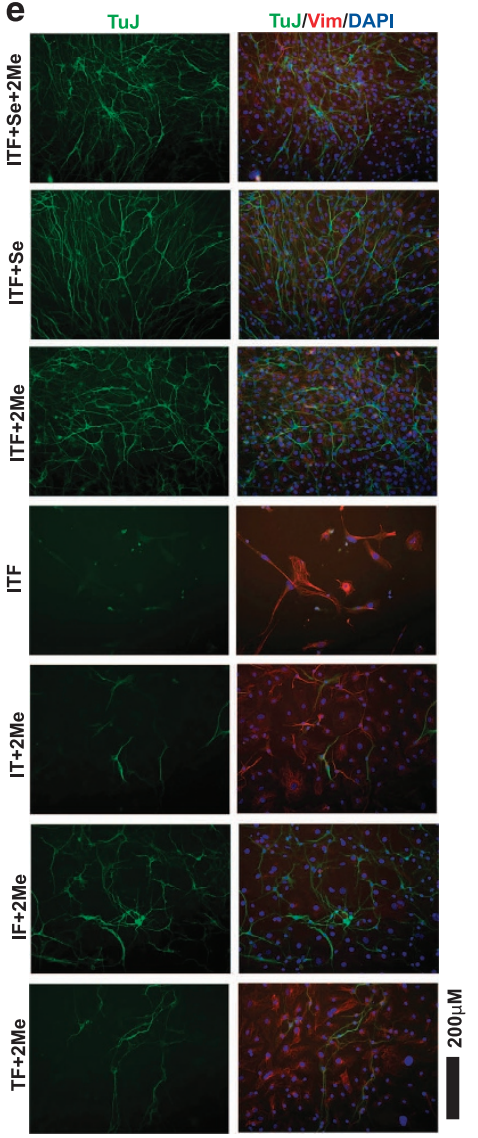

g
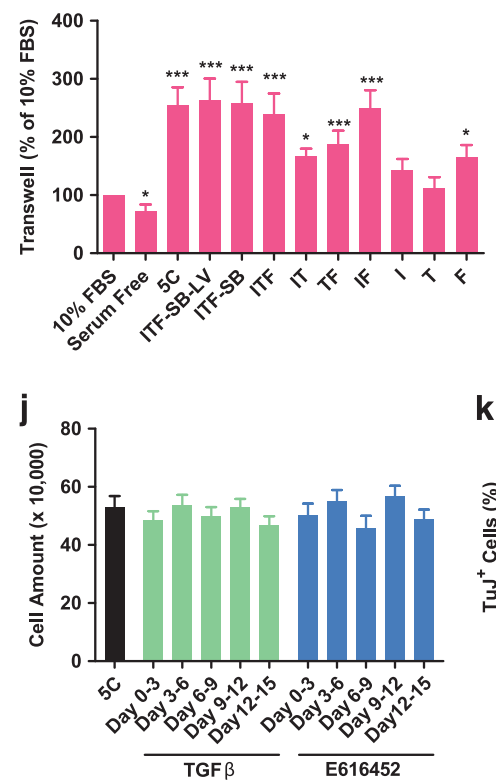

h
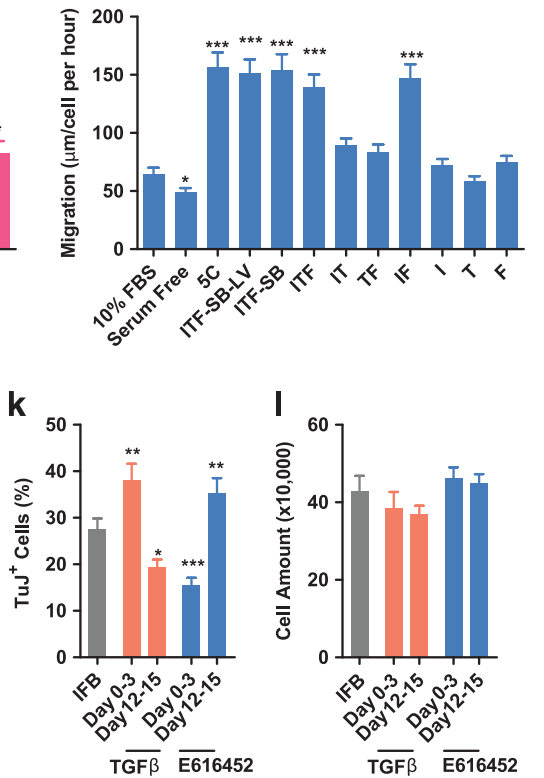

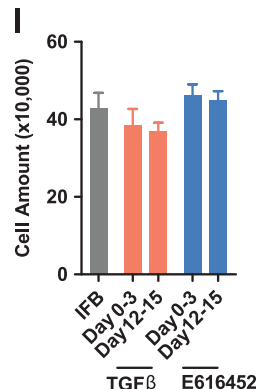

Figure 3 Sequential EMT-MET is essential for the induction. (a-e) The abilities of $5 \mathrm{C}$ and modified mediums to induce proliferation $(\mathbf{a}, \mathbf{c})$ and $\mathrm{TuJ}^{+}$cells $(\mathbf{b}, \mathbf{d})$ were determined with FACS on day 16 . Representative immunofluorescence images are provided to indicate the essential roles of insulin and bFGF (e). (f) Final cell amounts on day 16 were plotted against the percentages of $\mathrm{TuJ}^{+}$cells based on the results from PD0332991 (Figure 2j-l) and factor deduction (a-d). The shift between the two curves is indicated with a black arrow. (g, h) Transwell results and migration distances were used to determine cell migration induced by $5 \mathrm{C}$ and other modified mediums. (i-l) TGF $\beta$ and E616452 were used to induce EMT and MET, respectively, during the conversion induced by $5 \mathrm{C}$ or IFB medium. Proliferation rates and the number of TuJ ${ }^{+}$cells were determined on day 16. I, T, F, S, B (2me), L, and V was used to suggest that insulin, transferrin, bFGF, sodium selenite, 2-mercaptoethanol, LIF, and vitamin C, respectively, was supplemented in the basal DMEM/F12 (1:1) medium. 
hypothesis was sequential EMT-MET because it also facilitates iPSC generation [12].

Both insulin and bFGF increased cell migration as demonstrated using transwell assays, wound-healing assays and live-cell tracing (Figure $3 \mathrm{~g}$ and $\mathrm{h}$ and Supplementary Figure S5). In addition, as demonstrated by the expression of EMT or MET markers, insulin and bFGF were necessary and sufficient to induce sequential EMT-MET during the conversion (Supplementary Table S6). TGF $\beta$ and E616452 (also named Repsox) were then used to modulate the sequential EMT-MET (Supplementary Table S6). Inhibiting either early EMT or late MET impaired the conversion (Figure $3 \mathrm{i}$ and $\mathrm{j}$ ). Similar regulatory roles of TGF $\beta$ and E616452 were observed with neuronal conversion induced by IFB medium (Figure $3 \mathrm{k}$ and 1 ). Therefore, insulin- and bFGF-induced sequential EMT-MET is also required for the induction of $\mathrm{TuJ}^{+}$cells.

\section{Sox2 can replace sequential EMT-MET}

To establish the connection between sequential EMT-MET and the neuronal conversion, Pscan [20] was used to identify potential transcription factors that are directly upstream of the genes related to neuron projection in Figure 1a and $b$. The transcription factors whose binding motifs were over-represented in the listed genes were co-analysed with their expression changes during the induction (Supplementary Table S7). Sox2, whose expression during the conversion lies between MEFs and primary neurons (Supplementary Figure S3A), was identified as the most likely candidate, because of the over-representation of its binding motif and the significant expression change during the conversion (Supplementary Table S7). In addition, late MET, rather than early EMT, is more similar to neuronal conversion when considering EMT and metabolism changes (Supplementary Figure S3). Thus, as a MET inducer $[12,21]$, Sox 2 may play critical roles during the conversion.

The ability of insulin and bFGF to modulate the expression of Sox2 and its upstream regulator during neuron fate specification, Stat3 [22], was then determined (Supplementary Table S6). Insulin, together with bFGF, induced Stat3 up-regulation at the early stage (days 0-10) and down-regulation at the late stage (days 10-14; Figure 4a). Sox2 expression was up-regulated by insulin and bFGF at both the early and late stage (Figure 4a). Multiple inhibitors like MK2206, U73122, Go6983 and LDN193189 were used to determine the mediator between insulin/bFGF and Stat3/Sox2 (Supplementary Figure S7A-D).
MK2206, an Akt inhibitor, attenuated the up-regulation of Sox2 and Stat3 and impaired the induction of $\mathrm{TuJ}^{+}$cells (Supplementary Figure S7A-D), suggesting a pathway from insulin/bFGF to Akt and then to Stat3/Sox2.

As insulin and bFGF-induced neuronal conversion by accelerating cell proliferation and inducing sequential EMT-MET, the connection between sequential EMT-MET and up-regulated Stat3/Sox2 was studied [23]. Actually, Stat3 up-regulation was observed in more than $70 \%$ of EMT microarrays analysed previously (Supplementary Table S8 and [23]). In contrast to the universal up-regulation of Stat3, the up-regulation of Sox2 and the four representative neuron projection markers were enriched in data sets with strongly induced EMT (Supplementary Table S8 and [23]). Therefore, the following hypothesis was proposed. Insulin- and bFGF-induced early EMT up-regulated Stat3 and, subsequently, Sox2 and neuron projection genes. When Sox 2 expression reached a certain criterion, its ability to induce MET overwhelmed insulin- and bFGF-induced EMT, leading to the switch from EMT to MET (sequential EMTMET), the down-regulation of Stat3, and further conversion to neurons.

To confirm this hypothesis, TGF $\beta$ was used for the first 3 days, and E616452 was used for the last 3 days during the conversion. Both treatments facilitated neuronal conversion (Figure 3i-1), which correlated with enhanced Sox2 up-regulation on both days 10 and 14, Stat3 up-regulation on day 10 and Stat3 downregulation on day 14 (Figure 4a-c and Supplementary Table S6). Actually, by calculating the correlation between Stat3/Sox2 expression and the percentage of $\mathrm{TuJ}^{+}$cells, peaked up-regulation of Stat 3 on day 10 and the constant up-regulation of Sox2 across whole conversion related highly to the high conversion efficiency.

Other evidences also support this hypothesis. First, the two strong EMT inducers, insulin and bFGF, are difficult to induce late MET (Supplementary Figure $\mathrm{S} 3 \mathrm{G}$ and $\mathrm{H}$ ). In addition, Sox 2 bound to the locus of genes related to neuron projection in undifferentiated NSCs and resulted in their up-regulation during differentiation from NSCs to neurons, based on previous published RNA-seq and microarray results (Supplementary Table S9). Furthermore, Sox2 induced MET in MEFs cultured with FBS medium, in NSC differentiation and during reprogramming (Supplementary Figure S7E-G and Supplementary Table S10). Actually, overexpression of Sox 2 during 5C-induced conversion impaired the early EMT and facilitated the late MET (Supplementary Table S6). 

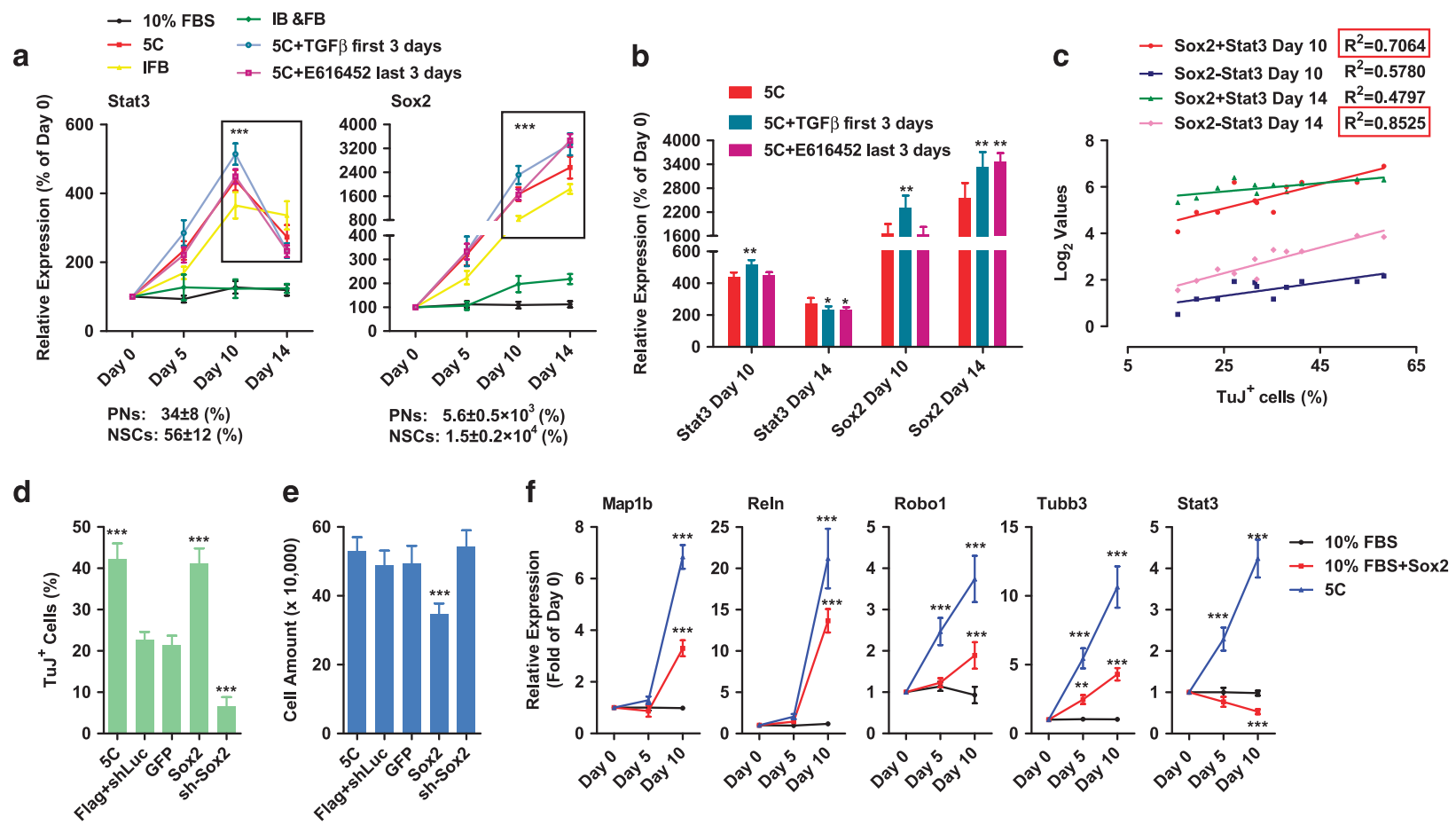
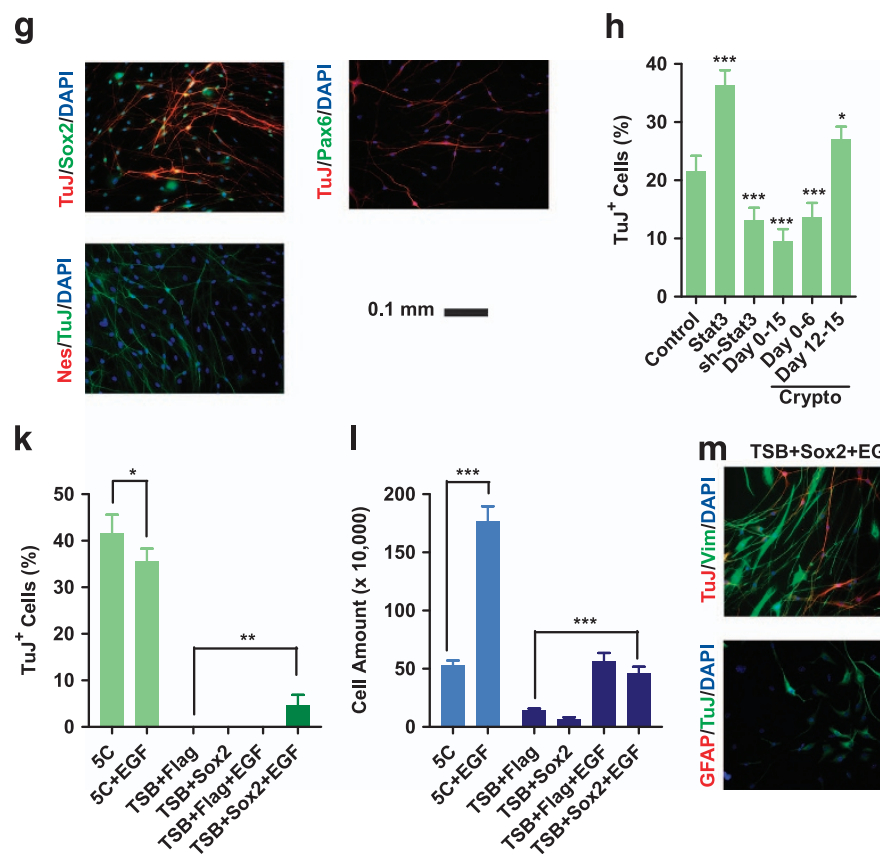

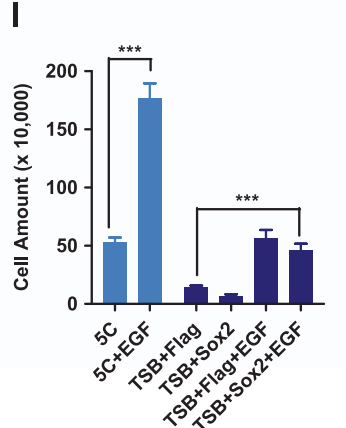

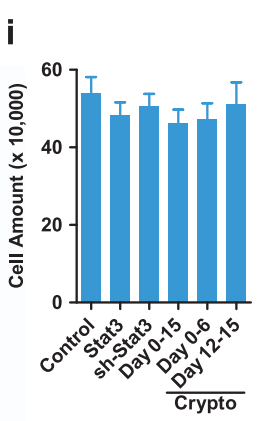
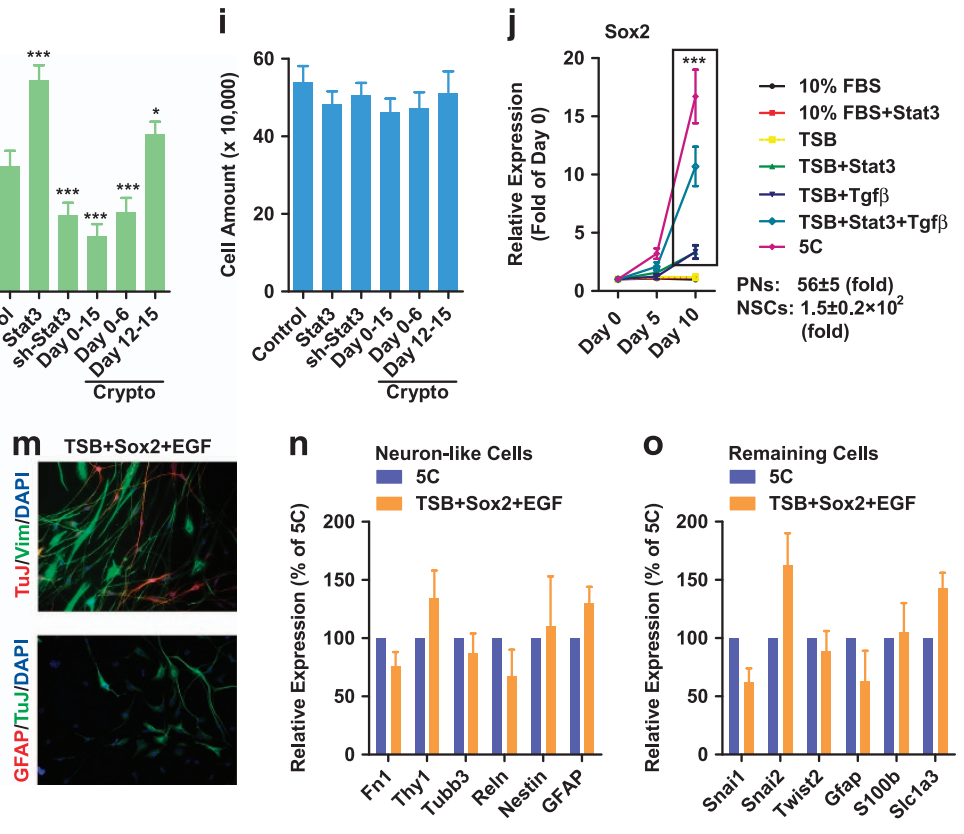

Figure 4 Sox2 replaces the sequential EMT-MET. (a) During neuronal conversion, insulin and bFGF regulated the expression of Stat 3 and Sox2, which could be modulated by TGF $\beta$ when used on days 0-3 and E616452 when used on days 12-15. The expression of Stat3 and Sox 2 in primary neurons (PNs) and NSCs are also provided. (b) The expression of Stat3 and Sox2 on days 10 and 14 are listed. (c) The expression of Stat 3 and Sox 2 and TuJ ${ }^{+}$percentages on day 16 that generated in Figure 3 were plotted against each other. The expression of Stat3 and Sox2 had higher correlation with the sum of the $\log _{2}$ increases of Stat3 and Sox 2 on day 10 and the difference of these two $\log _{2}$ changes on day 14 . $(\mathbf{d}-\mathbf{g})$ Sox 2 overexpression facilitated the induction of TuJ ${ }^{+}$cells $(\mathbf{d}, \mathbf{e})$. Sox2 overexpression up-regulated the expression of neuron projection genes rather than the NSC markers $(\mathbf{f}, \mathbf{g})$. (h, i) The abilities of Stat3 and its inhibitor (Crypto) to regulate the current conversion were determined. (j) The abilities of Stat 3 to regulate Sox 2 expression were determined in different medium. The expression of Stat3 and Sox 2 in PNs and NSCs are also provided. (k-o) Sox2 induced significant neuronal conversion with the help of EGF (k, I). The final cells were separated into two groups, neuron-like and remaining cells. The neuron-like were $\mathrm{TuJ}^{+}$and the remaining cells were $\mathrm{Vim}^{+}$but $\mathrm{GFAP}^{-}(\mathbf{m})$. These two types of cells were compared with $5 \mathrm{C}$-induced cells were by quantitative PCR (qPCR; $\left.\mathbf{n}, \mathbf{o}\right)$. 
To further confirm the hypothesis above, expression of Sox2 and Stat 3 was modulated during the conversion. Although retrovirus-mediated gene delivery impaired the conversion, Sox2 increased the percentage of $\mathrm{TuJ}^{+}$cells (Figure $4 \mathrm{~d}$ and e). As Sox 2 was able to up-regulate the four representative neuron projection genes, Maplb, Reln, Robol and Tubb3, in MEFs cultured with FBS medium (Figure 4f), an essential role for Sox2 during 5C-induced conversion was suggested. In addition, Sox2 promoted neuronal conversion without inducing the up-regulation of NSC markers, such as Nestin and Pax6 (Figure 4g). Sox2 overexpression decreased the percentages of both MEF-like and shrunken cells on day 14, but increased the percentage of neuron-like cells (Supplementary Figure S7H).

Stat 3 overexpression facilitated $\mathrm{TuJ}^{+}$cell induction, while Stat3 suppression with shRNA and cryptotanshinone (Crypto) inhibited this induction (Figure 4h and i). The ability of Stat 3 to induce Sox2 expression was confirmed in TSB rather than FBS medium (Figure 4j).

Impairing the early EMT with TGF $\beta$ decreased the ability of $5 \mathrm{C}$ to induce the current conversion. However, Sox2 overexpression attenuated the early EMT but promoted the conversion. In addition, considering the ability of early EMT to up-regulate Sox2, it is reasonable to suggest that the beneficial roles of early EMT during 5C-induced conversion can be attributed to Sox2 up-regulation at least partially. Thus, Sox2 may be able to replace sequential EMT-MET, especially the early EMT.

To confirm the hypothesis above, TSB medium was used since it was unable to induce sequential EMT-MET and Sox2 up-regulation (Supplementary Table S6). Although Sox2 was unable to induce $\mathrm{TuJ}^{+}$ cells in TSB medium, possibly because of the severe proliferation inhibition (Figure $4 \mathrm{k}, 1$ and $\mathrm{s}$ Supplementary Figure S7G), Sox2 induced low but significant levels of neuronal conversion with the help of epidermal growth factor (EGF; Figure $4 \mathrm{k}$ and 1 ). The $\mathrm{TuJ}^{+}$and remaining cells induced by Sox2 in $\mathrm{TSB}+\mathrm{EGF}$ were similar to those induced by $5 \mathrm{C}$ medium (Figure 4m-o).

Overexpression of Sox2 in TSB medium with EGF induced MET directly instead of early EMT (Supplementary Table S6), further supporting the hypothesis that Sox2 overexpression was a downstream effects of early EMT and led to further MET and conversion.

The ability of EGF to facilitate proliferation and to slightly inhibit $\mathrm{TuJ}^{+}$cell induction suggested that sequential EMT-MET and proliferation were critical and sufficient for current conversion. The neuron-like cells generated with Sox2 and EGF were not significantly different from those generated with $5 \mathrm{C}$ medium when considering the expression of several fibroblast and neuron markers (Figure 4n).

Sequential EMT-MET is also observed during the generation of iPSCs when the four Yamanaka factors, Oct4, Klf4, c-Myc and Sox2, are introduced in a particular sequence: $\mathrm{OK}+\mathrm{M}+\mathrm{S}$ [12]. The $5 \mathrm{C}$ medium was approximately twofold more efficient than traditional mES medium in inducing $\mathrm{GFP}^{+}$iPSC colonies with OKMS (Supplementary Figure S8A and B). Subsequent qPCR analysis suggested that $5 \mathrm{C}$ medium inhibited MET at the early stage but promoted it at the late stage (Supplementary Figure S8C and D). To validate this finding, Sox 2 was removed from the reprogramming system, and an even larger difference in reprogramming efficiencies was observed, which correlated with enhanced up-regulation of Stat3 and Sox2 (Supplementary Figure S8E and F).

\section{Other neuron-induction processes}

The other three reported protocols also induced $\mathrm{TuJ}^{+}$cells from somatic cells [8-10]. We then applied these protocols in MEFs, and all three protocols successfully induced $\mathrm{TuJ}^{+}$cells though with different efficiencies (Figure 5a-c). During the conversion induced by $5 \mathrm{C}$ medium or with the protocol provided by Pei Gang's laboratory [8], up-regulation of Stat3, Sox2 and EMT markers, such as Zeb1 and Slug, was observed. However, NeuroD1 up-regulation, which is considered a major mechanism for neuronal conversion [6, 7, 10], was not observed (Figure 5d and e). In contrast, the up-regulation of NeuroD1 but not Stat3, Sox2, Zeb1 or Slug was observed with the other two protocols (Figure 5f and g) [9, 10], suggesting that different routes may be employed during different neuronal conversions.

In addition, such hypothesis was supported by the different abilities of NeuroD1 and Sox2 to modulate different neuronal conversions. Overexpression of NeuroD1 impaired the conversions with Sox2 overexpression, like $5 \mathrm{C}$-induced or that reported by Pei's Lab, while facilitated the other two conversions (Figure 5h). Overexpression of Sox2 modulated the conversions just oppositely.

The major components of 5C medium, insulin and bFGF, were identified in four of the five conversion protocols, and the reason why the other protocols require additional compounds for the conversion might be the frequently used B27 (Figure 5c). A concentration 
a

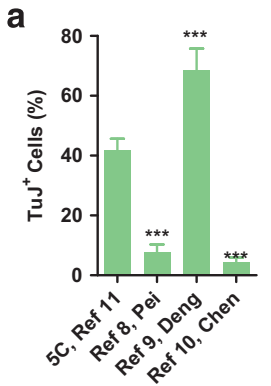

d

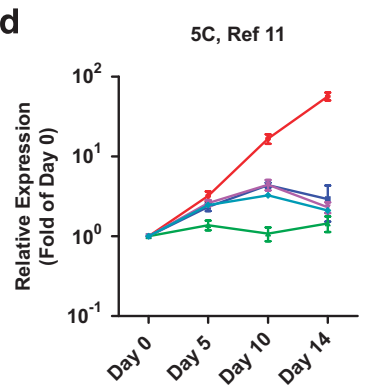

h

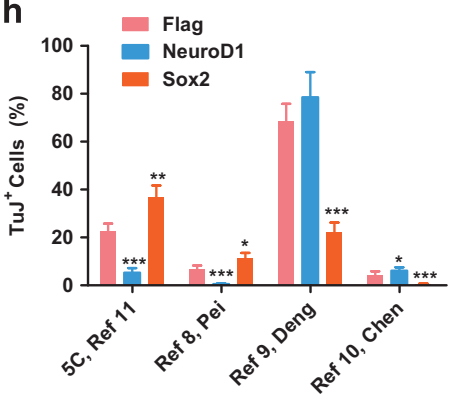

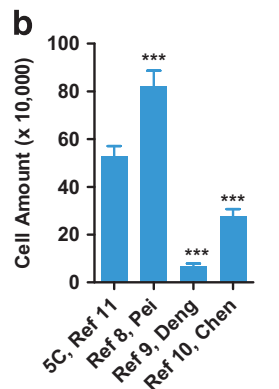
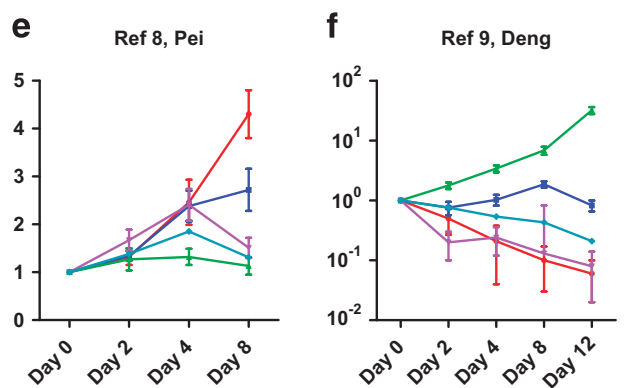

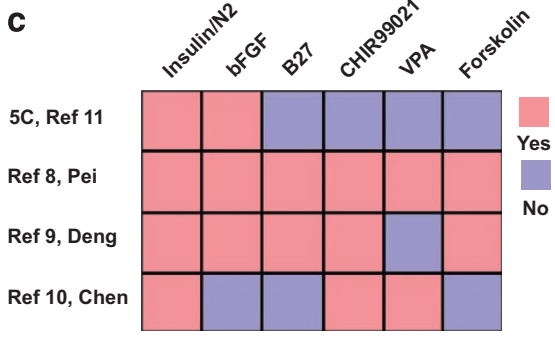

g Ref 10, chen

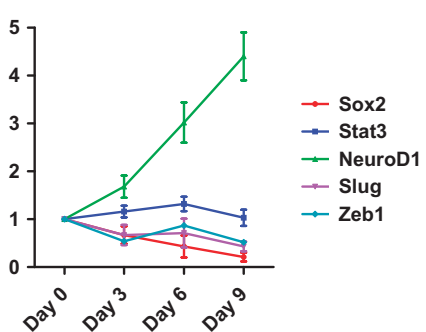

i

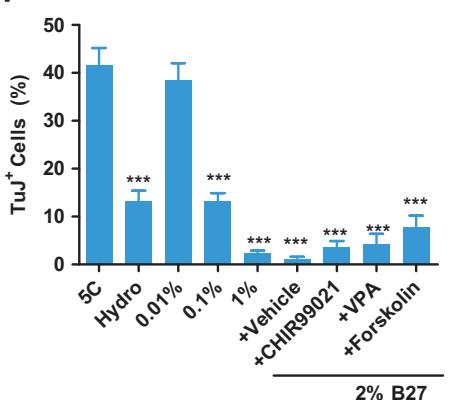

j

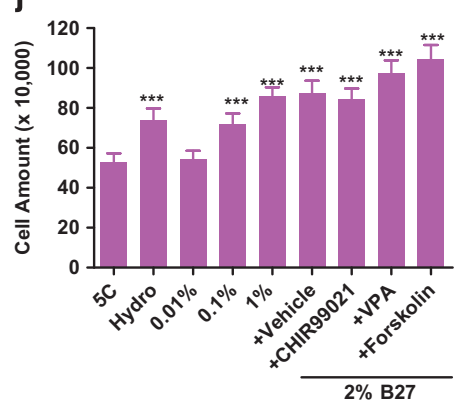

Figure 5 Neuronal conversion employs multiple pathways $(\mathbf{a}-\mathbf{g})$. Neuronal conversion was induced with $5 \mathrm{C}$ medium and other protocols from $[8,9,10]$. TuJ ${ }^{+}$cells were determined with FACS $(\mathbf{a}, \mathbf{b})$. The major components used in the induction phase of these protocols were compared $(\mathbf{c})$. The expression of several representative genes was determined with $\mathrm{gPCR}(\mathbf{d}-\mathbf{g})$. (h) The effects of NeuroD1 and Sox 2 overexpression on different neuronal conversions. (i, j) The effects of hydrocortisone (hydro) and B27 on the current conversion were determined.

of $0.1 \%$ B27 significantly inhibited the conversion (Figure $5 \mathrm{i}$ and $\mathrm{j}$ ). Although the exact concentrations of B27 gradients are not available [24], hydrocortisone (hydro), which has been suggested to promote proliferation of primary glial cells and fibroblasts $[25,26]$, significantly inhibited neuronal conversion (Figure 5i and j). The other commonly used components, CHIR99021, VPA and Forskolin/cAMP, counteracted B27 and rescued the inhibitory effects of B27 to different extents (Figure 5i and j).

\section{Discussion}

NeuroD1 is sufficient to convert astrocytes to glutamatergic neurons in vivo [6]. In addition, Isx9, which induces NeuroD1 expression via $\mathrm{Ca}^{2+}$ influx, is involved in neuronal conversion [9]. However, NeuroD1 overexpression significantly inhibited $\mathrm{TuJ}^{+}$ cell induction with the current $5 \mathrm{C}$ medium (Figure $5 \mathrm{~h}$ and i). NeuroD1, a key regulator during adult neurogenesis, can be co-stained with several NSC markers, including Pax6, PSA-NCAM and DCX [27]. The undetected up-regulation of NeuroD1, Pax6 and $D c x$ suggests that the conversion induced by $5 \mathrm{C}$ may represent a different way to acquire neuronal characteristics [11]. The ability of overexpressed NeuroD1 to suppress Sox2 further suggested the exclusivity of the conversions marked by NeuroDl or Sox2 up-regulation [28].

The migration inhibition, proliferation arrest and metabolic switch suggest that the late or MET stage (days 10-14) of the conversion is substantially closer to 
a neuronal conversion than the early or EMT stage (days 0-10; Supplementary Figure S9). The function of the early EMT stage is to prepare cells for subsequent conversion. In addition, MET is a necessary early step during reprogramming from MEFs to iPSCs [29], and introducing a temporary EMT before MET further facilitates the process $[12,30,31]$. Thus, we have hypothesized that the early EMT may prepare cells to adopt a better intermediate state for further cell conversion processes $[15,16]$. In the current study, Stat 3 and Sox 2 were identified as the downstream effectors of insulin- and bFGF-induced EMT. The low (around 150-200\%) but universal up-regulation of Stat3 during EMT supports its essential role. However, up-regulation of Sox2, Map1b, Reln, Robo1 and Tubb3 was observed only in samples with strongly induced EMT, suggesting the involvement of other downstream effectors of EMT (Supplementary Table S8).

As a MET inducer, Sox2 serves as the regulator for the switch from EMT to MET; high levels of EMT activate Sox2 expression and subsequently induce MET. Similar phenomena were also observed when we attempted to determine the optimal infection sequence of the four Yamanaka factors. Sox2 can be delivered later than the other three factors, and the optimal sequence is $\mathrm{OK}+\mathrm{M}+\mathrm{S}$ [12]. This hypothesis was confirmed by performing the reprogramming with OKMS and OKM in 5C or mES medium (Supplementary Figure S8), suggesting that the 5C-induced, Sox2-related sequential EMT-MET also functions during iPSC generation.

\section{Materials and Methods}

\section{Animal studies}

All procedures related to animal studies were performed in accordance with the National Institutes of Health Guide for the Care and Use of Laboratory Animals (NIH Publication No. 80-23) and were approved by the Institutional Review Board in Guangzhou Institutes of Biomedicine and Health. All efforts were made to minimize the number of animals used and their suffering.

Six- to eight-week-old CD-1 (ICR) male mice were housed in groups of three with free access to food and water. Mice were anesthetized by intraperitoneal injection with ketamine $\left(90 \mathrm{mg} \mathrm{kg}^{-1}\right)$ and xylazine $\left(10 \mathrm{mg} \mathrm{kg}^{-1}\right)$. Saline, 5C medium or IFB medium was then infused into the mouse brain $(2.1 \mathrm{~mm}$ posterior to the bregma, lateral 1.2 and $3.2 \mathrm{~mm}$ to the skull) with an osmatic minipump $\left(0.5 \mu \mathrm{h}^{-1}, 14\right.$ days, Model 2002 and Brain Infusion Kit 2, Alzet, Cupertino, CA, USA). Each group had six mice, which was sufficient for the statistical analysis of preliminary studies. No particular method of randomization was used to assign the mice within each cage to the three groups, but no significant differences, especially in body weight, were observed. No mouse was excluded from the final analysis. On day 14 , the connecting tube between the osmatic minipump and the brain infusion cannula was cut. The cannula was then sealed and kept in the mouse brain for an additional 2 weeks. On day 28 , the mice were perfused with $4 \%$ paraformaldehyde after anesthesia and subjected to further analyses.

Mouse brains fixed with $4 \%$ paraformaldehyde were cut into $13-\mu \mathrm{m}$ horizontal sections with a Leica EM FC7. Sections were prepared from $0.5 \mathrm{~mm}$ below to $2.0 \mathrm{~mm}$ above the end of brain infusion needle (3.7-1.2 $\mathrm{mm}$ to the skull). One in every twelve sections was analysed and used to re-construct the tissues inside and surrounding the needle track, to determine the volume of the tissue, to calculate GFAP intensity and to summarize the number of EdU ${ }^{+}$cells.

\section{Neuronal conversion}

Small-molecule compounds, growth factors and other cell culture materials used in current study are listed in Supplementary Table S1 with their final concentrations, catalog numbers and other necessary information required to repeat the current experiments.

MEFs were derived from 13.5-day ICR mouse embryos after removing the head and all internal organs. After recovery from freezing in liquid nitrogen, MEFs were cultured for two additional passages in non-coated plates with FBS medium. MEFs that normally attached strongly to the plate were further enriched. Thirty seconds of $0.25 \%$ trypsin treatment, followed by two gentle PBS washes, removed cells with neurogenic potential and weak attachment. Normally, $50000 \mathrm{MEFs}$ were plated per well after coating the 6-well plate with Matrigel for $0.5 \mathrm{~h}$. The $5 \mathrm{C}$ medium or other induction medium was used for 14 days (live-cell tracing, qPCR and RNA-seq) or 16 days (FACS analysis and cell counting). Half of the medium was replaced with fresh medium every 2 days.

Retrovirus was produced with Plat-E cells and pMXs-based retroviral vectors. After adding polybrene to a concentration of $4 \mu \mathrm{g} / \mathrm{ml}$, viral supernatant was used to infect MEFs twice, with a 24-h interval. $5 \mathrm{C}$ or other medium was used to replace viral supernatant $24 \mathrm{~h}$ after the second infection, and this time point was counted as hour 0 or day 0 .

Primary neuron cultures were prepared as described previously [32]. In brief, the hippocampus and cortex isolated from mice within 1 day after birth were dissociated with neuron isolation enzyme. Cells were cultured for 3 weeks before maturation with neuron medium. Half of the medium was replaced with glial cell conditioned neuron medium every 2 days.

Primary NSCs were prepared from 13-day ICR mouse embryos [33]. In brief, after the meninges were stripped off, the remaining tissues of the brain were cut into pieces, rinsed with PBS and dissociated with $0.05 \%$ trypsin for $10-15 \mathrm{~min}$. The dissociated cells were re-suspended in NSC medium. After the adherence of fibroblasts, the supernatant was cultured to form neurospheres. The NSCs were stored in liquid nitrogen after 5 additional passages to remove any possible contamination with other cells, such as fibroblasts.

As mentioned above, all primary cultures were prepared following previously published protocols. Marker gene expression was described in the manuscript. These cells were subjected 
to a mycoplasma test (MycoAlert Lonza, Allendale, NJ, USA) to ensure they were free of mycoplasma before use.

\section{Live-cell image tracing}

Live-cell tracing was performed with a Cell Observer (Zeiss, Germany) during the current conversions. Light-field pictures were captured every $60 \mathrm{~min}$. The time when FBS medium was replaced with $5 \mathrm{C}$ medium was recorded as hour 0 .

Cell tracing was achieved with self-developed software and help from manual correction. In brief, individual cells were identified in each image with the location of the geometric gravity centers, the perimeter-to-area ratios and the length-towidth ratios. Doubling time, $\mathrm{Td}$, was determined based on the $\log _{2}$ increase of the cell amount before and after a 24-h interval. The migration ability of one particular cell was determined as the distance between the cell on hour $n$ and on hour $n+1$. If untraceable, the closest cell on hour $n+1$ was used for calculation. The following criteria were applied when cells were classified based on their morphologies. Neuron-like cells have a length-to-width ratio over 5 and at least two neurite outgrowths around the cell body. Shrunken cells have a small cell size, a nearly speherical shape (length-to-width ratio $<1.5$ ), and a high nucleus-to-cytosol ratio (over 1:5). MEF-like cells have both a large size and a low nucleus-to-cytosol ratio (below 1:10). Other cells were considered unclassified.

Live-cell tracing was performed with density of $20000 \mathrm{MEFs}$ per well, as it is difficult to trace cells at 50000 cells per well or higher density. The Cell Observer normally captured two areas in each well of a six-well plate, which accounted for approximately one fourth of the well area. The self-developed software worked well on the first 7 days at 20000 cells per well density. At the late stage, the software tended to identify several neuron-like cells located together as one single cell. Thus, cells were manually identified to correct the results from the software. In summary, counting total cell amounts, identifying and counting the three major types of cells, and calculating the migration distance were performed every $24 \mathrm{~h}$ during the conversion, with both the selfdeveloped software and manual correction. Six independent replicates were analysed, each with $\sim 5000$ initial MEFs. The results are provided in Figures $1 \mathrm{f}-\mathrm{k}$ and $2 \mathrm{~b}-\mathrm{d}$.

Because the morphological changes and cell migration were strong during the conversion, the current self-developed software was only able to trace the cells before day 5. Thus, 500 initial MEFs from six representative replicates were selected and manually traced; the results are provided in Figure $2 \mathrm{e}-\mathrm{i}$ and Supplementary Figure S4. Random selection was achieved by dividing each picture captured by the Cell Observer into $5 \times 5$ or 25 equal fields and selecting the cells that were closest to the middle of each field. The initial 500 selected MEFs from six independent replicates were traced. The final percentages of different types of cells were similar to those generated with software and manual correction from a large quantity of initial MEFs (at least six independent replicates each, with more than 5000 initial MEFs).

\section{Generation of mouse iPSCs}

In brief, retroviruses encoding Oct4, Klf4, c-Myc and Sox2 were produced with Plat-E cells and pMXs-based retroviral vectors. The viral supernatants were then used to infect MEFs
(15 $000 \mathrm{MEFs}$ per well in a 12-well plate) with polybrene at $4 \mu \mathrm{g} \mathrm{ml}^{-1}$ [12]. The $\mathrm{mES}$ or $5 \mathrm{C}$ medium was used to replace the FBS medium on day 2 after two separate infections on days 0 and 1 . Half of the medium was replaced with free mES medium every day. GFP ${ }^{+}$colony counting was performed every 2 days from days $8-14$.

\section{$q P C R$}

Total RNA was extracted and reversed transcribed using the miScript system (QIAGEN, Valencia, CA), which also included a SYBR Green PCR kit following the manufacturer's instruction. qPCR was performed on the CFX96 Touch Real-Time PCR Detection System (Bio-Rad). $\beta$-actin was used as the internal control to normalize the results from different samples. The primers used are listed in Supplementary Table S10.

\section{Immunofluorescence and FACS}

The protocol followed those reported previously [11]. In brief, cells were fixed with $4 \%$ paraformaldehyde after removing the medium and washing three times with PBS. The $13-\mu \mathrm{m}$ cryostat sections were prepared from mice perfused with $4 \%$ paraformaldehyde. These samples were washed twice with PBS and blocked with PBS containing 10\% goat serum, 1\% bovine serum albumin and $0.3 \%$ Triton X-100. Antibodies were diluted with PBS containing 1\% goat serum, $1 \%$ bovine serum albumin and $0.3 \%$ Triton X-100 and incubated with the samples for 12 or $2 \mathrm{~h}$ at room temperature. Three PBS washes followed each antibody incubation. Immunofluorescence was detected with a Zeiss LSM810, and FACS assays were performed with a BD Accuri C6 flow cytometer (BD Biosciences, San Jose, CA, USA). Antibodies are listed in Supplementary Table S11.

TUNEL assays were performed with the ApopTag Fluorescein Direct In Situ Apoptosis Detection Kit (Millipore, Billerica, MA, USA) following the manufacturer's instructions. Apoptotic cells were stained with red fluorescence and counterstained with DAPI. Apoptosis (\%) was quantified by calculating the percentage of $\mathrm{TUNEL}^{+}$cells in the total $\mathrm{DAPI}^{+}$cells.

\section{Cell migration}

The migration abilities of cells were determined by woundhealing and transwell assays. MEFs were subjected to different treatments such as $5 \mathrm{C}$ medium, trypsinized and replated at a density of 400000 cells per well in a 6-well plate or in a transwell dish (3428, Corning, Inc., Corning, NY, USA). For transwell assays, cells that migrated out of the chamber were assessed $24 \mathrm{~h}$ later. For wound-healing assays, a 1-ml tip was used to create a wound $12 \mathrm{~h}$ after replating, and the cells that migrated into the wound area were assessed after an additional $12 \mathrm{~h}$.

\section{EMT and other score calculations}

Two methods were used to calculate EMT scores. The first method, which relied on the 130 genetic signatures of human EMT identified previously [34], was developed in our previous report [25]. In brief, the mouse genes homologous to the 130 human EMT signatures were identified based on information from Mouse Genome Informatics (MGI, http://informatics.jax. org/) and HUGO Gene Nomenclature Committee (HGNC, 
http://www.genenames.org/). These genes were divided into genes that were up-regulated and those that were downregulated during EMT. The expression changes of these genes were summarized from RNA-seq or microarray data sets after comparing experimental groups to the control group. EMT score $=\left(\right.$ sum of $\log _{2}$ values of up-regulated gene expression changes - sum of $\log _{2}$ values of down-regulated gene expression changes)/overall number of genes used for calculation.

The second method was based on the qPCR results of four up-regulated genes, Cdh2, Fn1, Slug, and Zeb1, and two downregulated genes, Epcam and Ocln, during EMT. The calculation method was similar.

The metabolism scores were calculated with the expression changes of genes in the oxidative phosphorylation (KEGG00190) and glycolysis pathways (KEGG00010). Metabolism score $=\left(\right.$ sum of $\log _{2}$ values of OX gene expression changes - sum of $\log _{2}$ values of Gly gene expression changes)/ overall number of genes used for calculation.

\section{EMT microarray data sets}

The 74 human and 31 mouse EMT microarray results have been previously collected and analysed [25]. In brief, searching 'epithelial-mesenchymal transition' or 'EMT' in GEO, removing the data sets that focused on primary cancer samples or tissues, and selecting the data sets for studying the EMT induced by TGF $\beta$ or Snai1/Slug/Twist overexpression resulted in 24 human and 17 mouse data sets. The biological replicates of the same treatment were averaged and further normalized to the control samples. If there were multiple treatments to induce EMT in one data set, the same control sample was used. The gene names in each data set were replaced with their official symbols in the downloaded annotations from MGI and HGNC. The data sets were merged based on the official symbols. The results were then transformed into $\log _{2}$ values. Finally, the data tables with 74 and 31 EMT-induction samples/pairs for human and mouse, respectively, were generated.

\section{$R N A$-seq and other data sets}

RNA-seq data during induction were generated previously and deposited in the Gene Expression Omnibus under the accession number GSE68902 [11]. Gene ontology and KEGG analyses were performed with the DAVID online tool [35]. Pscan analysis was performed to identify potential transcription factor binding sites [20]. The other data sets downloaded from GEO are listed in Supplementary Table S12.

\section{Statistical methods}

Experiments were repeated at least five times $(n \geq 5)$ except for RNA-seq. No samples were excluded from the final analysis. The data met normal distributions, and comparisons were performed between groups with similar variance. The data were analysed and compared by two-tailed Student's $t$-test, one-way analysis of variance with Dunnett's post hoc test, or two-way analysis of variance with Bonferroni's post hoc test using Prism 5 (GraphPad Software Inc., La Jolla, CA, USA). Error bars and ' $n$ ' represent s.d.'s (or standard errors if indicated) and the number of independent experiments, respectively. '*', '**' and '***' represent significant differences $(P<0.05),(P<0.01)$ and
$(P<0.001)$, respectively, versus the indicated control groups. The statistical information for each experiment or panel is listed in Supplementary Table S13.

\section{Conflict of Interest}

The authors declare no conflict of interest.

\section{Acknowledgements}

This work was supported by the National Natural Science Foundation of China (31422032, 31671475, U1601228, 91519305 and 31421004), the Key Research Program of Frontier Sciences of CAS (QYZDB-SSW-SMC031), the Guangdong Natural Science Foundation (2014A030308002), the Guangzhou Science and Technology Program (201607010239), the Guangzhou Health Care Collaborative Innovation Program (201508020250), the Guangdong Special Support Program (2014TQ01R157) and the Instrumentation Development Program by Ministry of Finance (ZDYZ2012-3). We gratefully thank the support from the Guangzhou Branch of the Supercomputing Center of CAS.

\section{Author contributions}

HZ and DP conceived and supervised the study and wrote the manuscript. HZ and $\mathrm{SH}$ designed the experiments and analysed the data. All authors except DP performed the experiments.

\section{References}

1 Okano H, Yamanaka S. iPS cell technologies: significance and applications to CNS regeneration and disease. Mol Brain 2014; 7: 22.

$2 \mathrm{Xu} \mathrm{J}, \mathrm{Du} \mathrm{Y}$, Deng $\mathrm{H}$. Direct lineage reprogramming: strategies, mechanisms, and applications. Cell Stem Cell 2015; 16: 119-134.

3 Kim J, Efe JA, Zhu S et al. Direct reprogramming of mouse fibroblasts to neural progenitors. Proc Natl Acad Sci USA 2011; 108: 7838-7843.

4 Cheng L, Hu W, Qiu B et al. Generation of neural progenitor cells by chemical cocktails and hypoxia. Cell Res 2014; 24: 665-679.

5 Vierbuchen T, Ostermeier A, Pang ZP, Kokubu Y, Sudhof TC, Wernig M. Direct conversion of fibroblasts to functional neurons by defined factors. Nature 2010; 463 : 1035-1041.

6 Guo Z, Zhang L, Wu Z, Chen Y, Wang F, Chen G. In Vivo direct reprogramming of reactive glial cells into functional neurons after brain injury and in an Alzheimer's disease model. Cell Stem Cell 2014; 14: 188-202.

7 Cheng L, Gao L, Guan W et al. Direct conversion of astrocytes into neuronal cells by drug cocktail. Cell Res 2015; 25: 1269-1272.

$8 \mathrm{Hu}$ W, Qiu B, Guan W et al. Direct conversion of normal and Alzheimer's disease human fibroblasts into neuronal cells by small molecules. Cell Stem Cell 2015; 17: 204-212. 
9 Li X, Zuo X, Jing J et al. Small-molecule-driven direct reprogramming of mouse fibroblasts into functional neurons. Cell Stem Cell 2015; 17: 195-203.

10 Zhang L, Yin JC, Yeh H et al. Small molecules efficiently reprogram human astroglial cells into functional neurons. Cell Stem Cell 2015; 17: 735-747.

11 He S, Guo Y, Zhang Y et al. Reprogramming somatic cells to cells with neuronal characteristics by defined medium both in vitro and in vivo. Cell Regen (Lond) 2015; 4: 12.

12 Liu X, Sun H, Qi J et al. Sequential introduction of reprogramming factors reveals a time-sensitive requirement for individual factors and a sequential EMT-MET mechanism for optimal reprogramming. Nat Cell Biol 2013; 15: 829-838.

13 Chaffer CL, Thompson EW, Williams ED. Mesenchymal to epithelial transition in development and disease. Cells Tissues Organs 2007; 185: 7-19.

14 Thiery JP, Acloque H, Huang RY, Nieto MA. Epithelialmesenchymal transitions in development and disease. Cell 2009; 139: 871-890.

15 Li X, Pei D, Zheng H. Transitions between epithelial and mesenchymal states during cell fate conversions. Protein Cell 2014; 5: 580-591.

16 Zheng H, Hutchins AP, Pan G, Li Y, Pei D, Pei G. Where cell fate conversions meet Chinese philosophy. Cell Res 2014; 24: 1162-1163.

17 Tian E, Sun G, Sun G et al. Small-molecule-based lineage reprogramming creates functional astrocytes. Cell Rep 2016; 16: 781-792.

18 Gascon S, Murenu E, Masserdotti G et al. Identification and successful negotiation of a metabolic checkpoint in direct neuronal reprogramming. Cell Stem Cell 2016; 18: 396-409.

19 Fry DW, Harvey PJ, Keller PR et al. Specific inhibition of cyclin-dependent kinase 4/6 by PD 0332991 and associated antitumor activity in human tumor xenografts. Mol Cancer Ther 2004; 3: 1427-1438.

20 Zambelli F, Pesole G, Pavesi G. Pscan: finding over-represented transcription factor binding site motifs in sequences from co-regulated or co-expressed genes. Nucleic Acids Res 2009; 37: W247-W252.

21 Li X, Xu Y, Chen Y et al. SOX2 promotes tumor metastasis by stimulating epithelial-to-mesenchymal transition via regulation of WNT/beta-catenin signal network. Cancer Lett 2013; 336: 379-389.

22 Foshay KM, Gallicano GI. Regulation of Sox 2 by STAT3 initiates commitment to the neural precursor cell fate. Stem Cells Dev 2008; 17: 269-278.

23 Liang L, Sun H, Zhang W et al. Meta-analysis of EMT datasets reveals different types of EMT. PLoS ONE 2016; 11: e0156839.

24 Brewer GJ, Torricelli JR, Evege EK, Price PJ. Optimized survival of hippocampal neurons in B27-supplemented
Neurobasal, a new serum-free medium combination. J Neurosci Res 1993; 35: 567-576.

25 Chen G, Gulbranson DR, Hou Z et al. Chemically defined conditions for human iPSC derivation and culture. Nat Methods 2011; 8: 424-429.

26 Bottenstein J. Growth and Differentiation of Neural Cells in Defined Media. Springer, New York, NY, USA. 1985.

27 von Bohlen Und Halbach O. Immunohistological markers for staging neurogenesis in adult hippocampus. Cell Tissue Res 2007; 329: 409-420.

28 Evsen L, Sugahara S, Uchikawa M, Kondoh H, Wu DK. Progression of neurogenesis in the inner ear requires inhibition of Sox2 transcription by neurogenin1 and neurod1. J Neurosci 2013; 33: 3879-3890.

29 Li R, Liang J, Ni S et al. A mesenchymal-to-epithelial transition initiates and is required for the nuclear reprogramming of mouse fibroblasts. Cell Stem Cell 2010; 7: 51-63.

30 Di Stefano B, Sardina JL, van Oevelen C et al. C/EBPalpha poises B cells for rapid reprogramming into induced pluripotent stem cells. Nature 2014; 506: 235-239.

31 Unternaehrer JJ, Zhao $\mathrm{R}$, Kim $\mathrm{K}$ et al. The epithelial-mesenchymal transition factor SNAIL paradoxically enhances reprogramming. Stem Cell Rep 2014; 3: 691-698.

32 Kaech S, Banker G. Culturing hippocampal neurons. Nat Protoc 2006; 1: 2406-2415.

33 Li W, He S, Zhou Y et al. Neurod1 modulates opioid antinociceptive tolerance via two distinct mechanisms. Biol Psychiatry 2014; 76: 775-784.

34 Groger CJ, Grubinger M, Waldhor T, Vierlinger $\mathrm{K}$, Mikulits W. Meta-analysis of gene expression signatures defining the epithelial to mesenchymal transition during cancer progression. PLoS ONE 2012; 7: e51136.

35 Huang da W, Sherman BT, Lempicki RA. Systematic and integrative analysis of large gene lists using DAVID bioinformatics resources. Nat Protoc 2009; 4: 44-57.

(Supplementary Information is linked to the online version of the paper on the Cell Discovery website.)

(i) This work is licensed under a Creative Commons Attribution 4.0 International License. The images or other third party material in this article are included in the article's Creative Commons license, unless indicated otherwise in the credit line; if the material is not included under the Creative Commons license, users will need to obtain permission from the license holder to reproduce the material. To view a copy of this license, visit http://creativecommons.org/licenses/by/4.0/

(C) The Author(s) 2017 